\title{
VARIACIÓN MORFOLÓGICA DE CORYPHANTHA (CACTACEAE): UN ENFOQUE MULTIVARIADO
}

\author{
Balbina VázQuez-Benítez ${ }^{1}$, Salvador Arias ${ }^{1,3}$ y Armando Cervantes-Sandoval ${ }^{2}$ \\ ${ }^{1}$ Universidad Nacional Autónoma de México, Instituto de Biología, Jardín \\ Botánico, Apdo. postal 70-614, México, D.F., México. \\ ${ }^{2}$ Universidad Nacional Autónoma de México, Facultad de Estudios Superiores \\ Zaragoza, Laboratorio de Aplicaciones Computacionales, México, D.F., México. \\ ${ }^{3}$ Autor para la correspondencia: sarias@ib.unam.mx
}

\section{RESUMEN}

Coryphantha tiene entre 43 y 67 especies. Los patrones de variación morfológica del género se han interpretado de distintas formas y han conducido a una taxonomía inestable, de manera que aún no se ha establecido un consenso en la delimitación de las especies. Clasificaciones previas de Coryphantha se han basado en caracteres cualitativos. Para dilucidar y circunscribir especies de Coryphantha se emplearon diferentes técnicas de análisis multivariado. Se muestrearon un total de 1840 individuos, 467 ejemplares en campo y 1373 registros herborizados de 48 taxa del género. Se emplearon 28 caracteres vegetativos y reproductivos de los cuales 17 fueron cuantitativos y 11 cualitativos. El análisis de conglomerados indicó la presencia de dos grandes grupos organizados por la presencia o ausencia de glándulas extraflorales. Los análisis discriminantes para cada subgrupo formado por los análisis de conglomerados permitieron circunscribir con base en variables morfométricas a la mayoría de las especies analizadas. Con base en los caracteres morfológicos y los análisis multivariados se discute el reconocimiento de categorías taxonómicas a nivel de especie o subespecie. Se reconocen 45 especies y tres subespecies.

Palabras clave: análisis de conglomerados, análisis discriminante, Cactaceae, Coryphantha, taxonomía.

\section{ABSTRACT}

Coryphantha consists of 43 to 67 species. This genus exhibit patterns of morphological variations that have been understood differently and have led to an unstable 
taxonomy, resulting in the fact that a consensus on the delimitation of species has yet to be reached. Previous classifications are based on qualitative characters. In order to clarify and circumscribe species of Coryphantha, different multivariate analysis techniques were used. A total of 1840 individuals among 48 taxa were examined; 467 in the field and 1373 from herbarium specimens. We used 28 vegetative and reproductive characters of which 17 were quantitative and 11 qualitative. Cluster analysis indicated the presence of two major groups based on the presence or absence of extrafloral glands. Discriminant analysis for each subgroup consisting of the cluster analysis allowed circumscription based on morphometric variables of the majority of the analyzed species. Based on morphological characters and multivariate analysis, recognition of taxonomic categories at species or subspecies level is discussed. 45 species and three subspecies are recognized.

Key words: Cactaceae, cluster analysis, Coryphantha, discriminant analysis, taxonomy.

\section{INTRODUCCIÓN}

Coryphantha es un miembro de la tribu Cacteae, subfamilia Cactoideae, familia Cactaceae. Dentro de Cacteae es el segundo género con mayor riqueza de especies, después de Mammillaria. Coryphantha fue designado como género por Lemaire (1868) a partir de una propuesta realizada por Engelmann (1856), quien inicialmente lo erigió como un subgénero de Mammillaria, para separar a las especies que presentan floración en el ápice del tallo. Bajo la circunscripción actual, Coryphantha incluye a las especies cuyos caracteres diagnósticos son la combinación de flores que surgen en el ápice del tallo, tubérculos del tallo con surco en la madurez y semillas con testa reticulada (Dicht y Lüthy, 2005a; Hunt, 2006). Se distribuye desde el extremo sur de Estados Unidos de América (Arizona, Nuevo México y Texas) (Bravo-Hollis y Sánchez-Mejorada, 1991; Guzmán et al., 2003) hasta el sur de México (Guerrero y Oaxaca), con una notable diversidad en la provincia fisiográfica del Altiplano Mexicano (Rzedowski, 1978). Las especies del género son comunes en los matorrales xerófilos y pastizales, aunque algunas prefieren los bosques tropicales caducifolios y los bosques de coníferas (Dicht y Lüthy, 2005a).

El conocimiento taxonómico del género es limitado, en parte debido a la variación morfológica que exhiben las especies y a los cambios fenotípicos que experimentan en las diferentes etapas de su desarrollo. Así, atributos como la forma y tamaño del tallo, el número, color y orientación de las espinas cambian en función del estado de desarrollo del espécimen, por lo que las descripciones con base en 
organismos juveniles fueron distintas a las de los reproductivos, lo cual ha generado incertidumbre en la delimitación taxonómica de varias especies. Esto sucede por ejemplo con Coryphantha salinensis en la que los ejemplares juveniles presentan un tallo de forma globosa y sus areolas carecen de espinas centrales, mientras que en estado reproductivo los tallos son de forma ovoide y pueden presentar hasta cuatro espinas centrales (Vázquez-Benítez, datos no publicados). Algunas especies de Coryphantha se confunden con elementos de otros géneros por compartir caracteres vegetativos en estado juvenil, como son Escobaria, Mammillaria y Neolloydia. No obstante, uno de los caracteres casi constante en Coryphantha es el color verde o ligeramente amarillento de los frutos maduros, mientras que en Escobaria los frutos maduros son rojos. Sin embargo, en algunas ocasiones especies de Coryphantha desarrollan frutos con tintes rojizos, por ejemplo C. gracilis (Bremer y Lau, 1977), C. bumamma y C. pycnacantha (Vázquez-Benítez obs. pers.). Asimismo, la variación de forma y color de la semilla llega a traslaparse con la de Escobaria (Barthlott y Hunt, 2000). En consecuencia, el número de especies en Coryphantha es variable, ya que Lemaire (1868) reconoció 25 especies, Zimmerman (1985) 67, Bravo-Hollis y Sánchez-Mejorada (1991) 59, mientras que Dicht y Lüthy (2001) y Hunt (2006) indican sólo 43.

Bravo-Hollis y Sánchez-Mejorada (1991) establecieron una clasificación infragenérica de Coryphantha con base en la presencia de un surco en los tubérculos y de glándulas extraflorales. Así, reconocen las series Macromeres, Aulacothelae y Glanduliferae. En la primera serie ubican a C. macromeris que tiene surcos incompletos en la cara adaxial de los tubérculos. Los representantes de Aulacothelae tienen surco en los tubérculos pero carecen de glándulas extraflorales, mientras que las especies de Glanduliferae están caracterizadas por presentar surco y glándulas. Por su parte, Dicht y Lüthy (2001) reconocieron dos subgéneros para conjuntar a las especies sin glándulas extraflorales (Coryphantha) y aquellas con glándulas extraflorales (Neocoryphantha).

Los estudios filogenéticos en Coryphantha son preliminares pero relevantes. Es parte del clado Mammillaria (Mammilloid clade, Butterworth et al., 2002) que incluye a géneros como Escobaria, Neolloydia, Ortegocactus y Pelecyphora (Butterworth y Wallace, 2004; Bárcenas et al., 2011; Hernández-Hernández et al., 2011). En particular, las relaciones entre Escobaria y Coryphantha han sido controversiales, ya que para algunos autores representan un solo género (Zimmerman, 1985), mientras que otros los reconocen como géneros distintos (Bravo-Hollis y SánchezMejorada, 1991; Dicht y Lüthy, 2001; Guzmán et al., 2003; Hunt, 2006). Un conflicto semejante existió con Cumarinia odorata, que fue descrita en Coryphantha 
y posteriormente excluida por caracteres de la semilla y del fruto (Buxbaum, 1951). Existen dos aspectos significativos en los avances filogenéticos: por una parte que Coryphantha posiblemente no es monofilético y por otro lado que es necesario un mejor conocimiento sobre el número de especies que actualmente integran al género, para poder realizar un análisis filogenético completo.

Existen dos estudios monográficos sobre Coryphantha (Zimmerman, 1985; Dicht y Lüthy, 2005a), con un aporte significativo en el reconocimiento de los caracteres morfológicos de importancia taxonómica. Con base en esa información, el objetivo de la presente investigación fue estudiar la variación morfológica en Coryphantha y su posible contribución a la circunscripción taxonómica de las especies, mediante el empleo de análisis multivariados.

\section{MATERIALES Y MÉTODOS}

Material biológico y caracteres morfológicos

Se examinaron 1373 registros en los herbarios ARIZ, ENCB, FESI, FEZA, Hinton, IEB, KEW, MEXU, MO, TEX/LL, UMO, US, USON y XAL. En los herbarios estadounidenses y el británico se recabaron los datos a través del Sistema Nacional de Información sobre Biodiversidad de México (SNIB) de CONABIO. Los datos obtenidos fueron considerados para las evaluaciones cualitativas cuando se reunió la condición reproductiva y para generar el patrón de distribución del género. De la información geográfica contenida en los herbarios, de la literatura taxonómica (Bravo-Hollis y Sánchez-Mejorada, 1991; Dicht y Lüthy, 2005a; Arias et al., 2012,) y de la experiencia de los autores en colectas previas, se seleccionaron 49 localidades en México donde se distribuye el género (Apéndice).

Se examinaron 467 ejemplares en estado reproductivo de 48 taxa de Coryphantha (Apéndice). Se obtuvieron imágenes con escala, a partir de las cuales se evaluaron diferentes caracteres (Cuadro 1). Las mediciones de los rasgos cuantitativos se obtuvieron con el programa AxioVision LE (Zeiss, 2009), utilizando las imágenes obtenidas en campo y de los herbarios. Se evaluaron 10 ejemplares por especie, pero debido a su distribución restringida, se muestrearon siete para C. hintoniorum, C. pulleineana y C. sulcata. La presencia de residuos florales o frutales fueron los indicadores de la madurez. Los datos de distribución geográfica de las especies fueron obtenidos de material de herbario, de la literatura taxonómica y de la experiencia de los autores en colectas previas. 
Cuadro 1. Caracteres cualitativos y cuantitativos analizados. Los caracteres métricos fueron medidos en $\mathrm{cm}$.

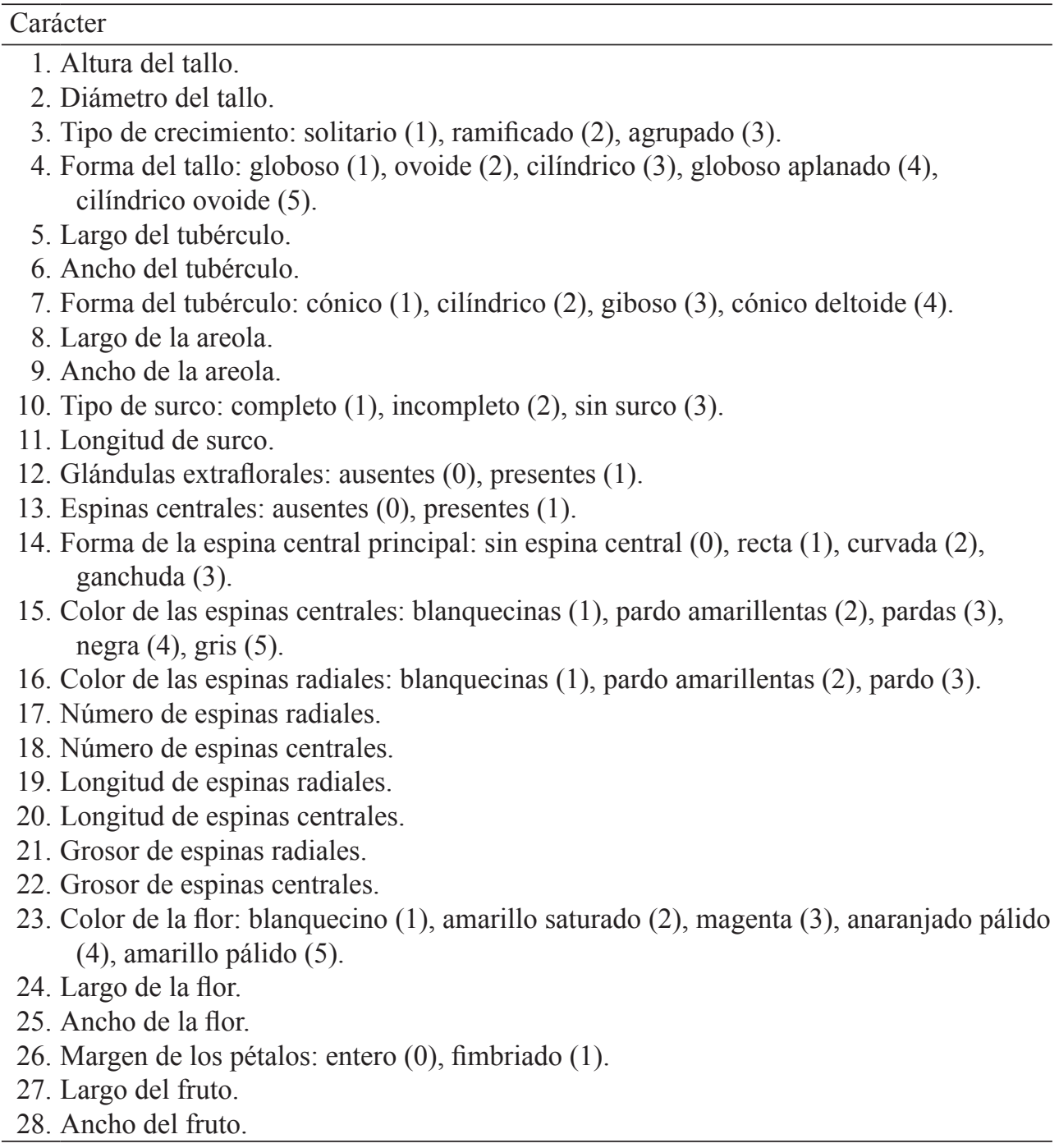

Se registraron 28 caracteres vegetativos y reproductivos para cada espécimen, de los cuales 17 fueron cuantitativos y 11 cualitativos (Cuadro 1). Para altura y diámetro se realizó una sola medida, para los caracteres restantes se registraron promedios de 10 mediciones de la parte media del tallo. Los rasgos florales y 
frutales se evaluaron en estructuras deshidratadas provenientes de ejemplares de MEXU y de las localidades visitadas en campo. Mediciones de flores y frutos en fresco y deshidratados indicaron que estos últimos reflejan del 15 al 20 por ciento de disminución en su tamaño. Para los caracteres cualitativos se registró la condición más frecuente.

Análisis de datos

Se construyó una base de datos de 28 variables y 467 ejemplares. La base de datos inicial fue dividida en dos bases, una cualitativa de 11 variables y otra cuantitativa de 17 variables. Debido a que los caracteres cualitativos han sido extensamente empleados en la formación de grupos dentro del género Coryphantha, se llevó a cabo un análisis de agrupamiento con datos categóricos para examinar el patrón de relaciones entre OTU's (especies).

Los estados de carácter de los rasgos cualitativos fueron asignados de acuerdo con una inspección visual de la variación morfológica entre las diferentes especies y fueron codificados como caracteres binarios o multiestado sin un orden específico. Se empleó el módulo SIMQUAL del programa NTSYS (Rohlf, 1998), con el coeficiente de emparejamiento simple (SM) y análisis de agrupamiento mediante ligamiento promedio (UPGMA). Los subgrupos derivados del análisis de agrupamiento inicial con variables cualitativas fueron sometidos a un análisis de conglomerados con variables morfométricas. Para este análisis se empleó la media aritmética de cada una de las 17 variables cuantitativas por especie y el método Ward de clasificación jerárquica aglomerativa y la distancia euclideana. A los grupos formados en el análisis de conglomerados (AC) con variables cuantitativas, se les aplicó un análisis de componentes principales (ACP) para conocer los pesos de las variables con mayor correlación que contribuían a la formación de conjuntos de especies. El criterio empleado fue seleccionar los componentes con eigenvalores mayores a 1.0. Para la ejecución de los ACP se utilizó la matriz de datos cuantitativos y cada espécimen fue tratado como una unidad taxonómica operacional (OTU). Para determinar si las mediciones de los caracteres morfológicos podrían discriminar significativamente entre los taxa definidos por Dicht y Lüthy (2001), se empleó un análisis discriminante (AD) para los grupos pre-clasificados de especies en el análisis de conglomerados. Para valorar la significancia estadística de las funciones discriminantes obtenidas se utilizó el estadístico Lambda de Wilks (Barker y Barker, 1984). Los análisis estadísticos con variables cuantitativas fueron ejecutados con el programa StatGraphics Centurion XV (Statpoint Inc., 2005). 


\section{RESULTADOS}

Caracteres cualitativos

El análisis de agrupamiento efectuado con 11 variables cualitativas revela la existencia de dos conjuntos (Fig. 1). El grupo I está integrado por 47 taxa y el grupo II sólo por Coryphantha macromeris. El subgrupo IA está conformado por 32 especies que carecen de glándulas extraflorales, en tanto que el conjunto IB está constituido por 15 especies que presentan glándulas extraflorales (Fig. $3 \mathrm{H}$ ). En ambos sub-conjuntos hay separación de grupos más pequeños definidos en función de la similitud morfológica cualitativa.

Del total, 77\% (37 especies) tienen crecimiento solitario y aunque en la mayoría de ellas se pueden presentar ramificaciones, no es la condición más frecuente (Fig. 2A). En Coryphantha durangensis, C. erecta, C. glassii, C. jalpanensis, C. macromeris, C. maiz-tablasensis y C. pulleineana el crecimiento ramificado es una condición constante (Fig. 2B). Coryphantha calipensis, C. nickelsiae y C. pseudoechinus forman agrupamientos no ramificados constituidos hasta por 20 especímenes independientes (Fig. 2C). Las diferencias entre el crecimiento ramificado y el agrupamiento no ramificado es posible apreciarlas a raíz desnuda.

La forma del tallo varía ampliamente entre y dentro de las especies de Coryphantha. Las formas dominantes del tallo son globosa (Fig. 2D), en 33\% (16 especies) y ovoide (Fig. 2E) en 31\% (15). El tallo cilíndrico se presenta en ocho especies (Fig. 2F), cilíndrica-ovoide en cinco (Fig. 2G) y globosa deprimida en cuatro (Fig. 2H). La forma cónica del tubérculo (Fig. 3A) prevalece en 24 especies $(50 \%)$, seguida por la forma cilíndrica en $25 \%$ de ellas (Fig. 3B). Las formas gibosa y cónico-deltoide del tubérculo fueron las menos frecuentes con ocho y cuatro especies respectivamente (Figs. 3C, D). En general, la forma de los tubérculos varía en función de la posición que ocupen en el tallo. Los tubérculos más jóvenes de la región apical tienden a ser cercanamente cilíndricos y los más longevos de la región basal son cónicos de escasa altura, mientras que en la zona media los tubérculos pueden ser cónicos, cónicos-deltoides, cilíndricos o gibosos según la especie.

El 94\% de las especies (45) desarrollan un surco completo en la cara adaxial del tubérculo en la etapa reproductiva (Fig. 3E). Solo Coryphantha macromeris desarrolla un surco incompleto (Fig. 3F) y en los ejemplares examinados de C. vogtherriana y C. werdermannii no se observó el surco (Fig. 3G). Hasta $79 \%$ de las especies (38) tienen espinas centrales como un carácter constante. Coryphantha bumamma, C. elephantidens, C. maiz-tablasensis, C. nickelsiae 


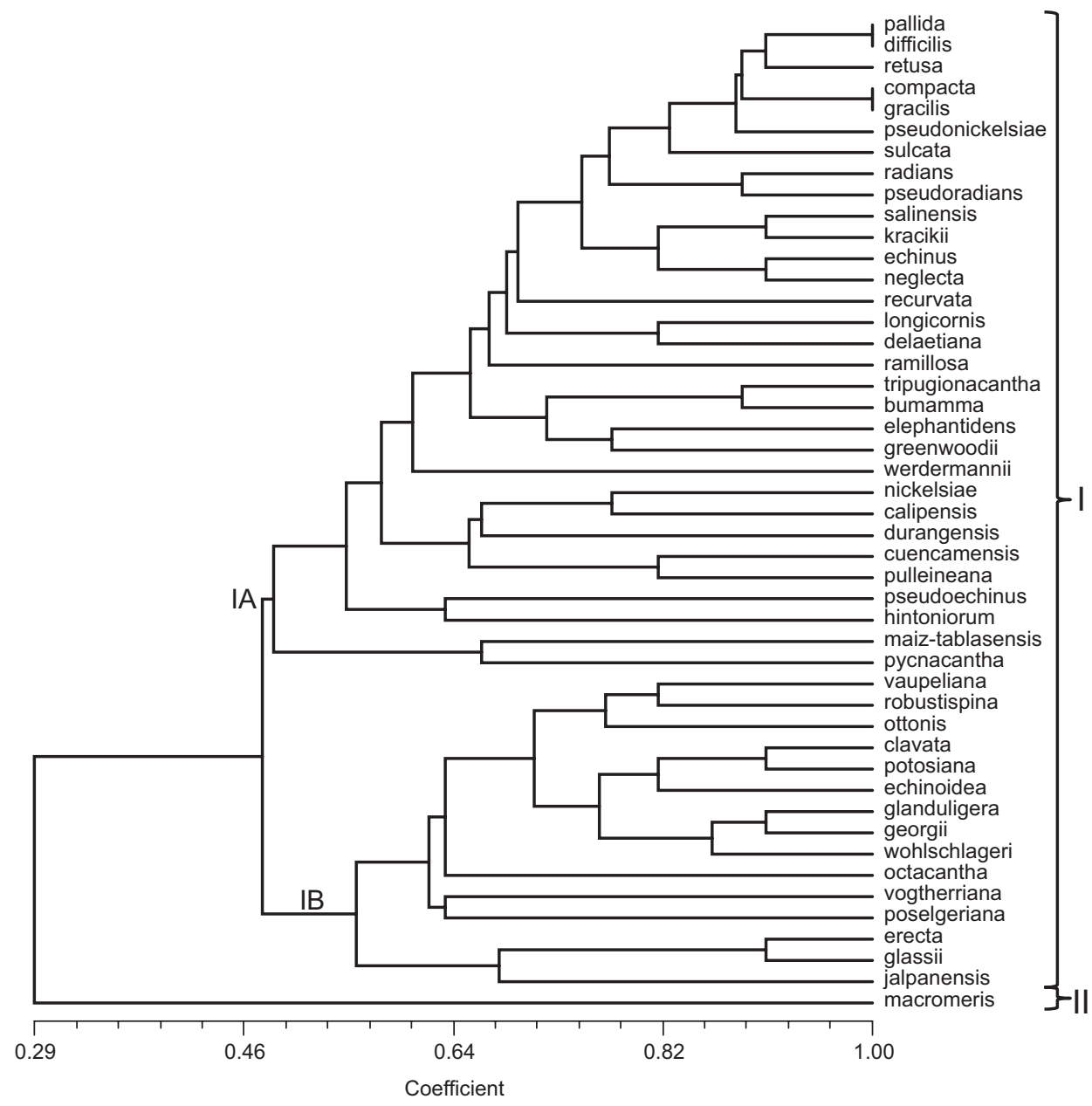

Fig. 1. Agrupamiento de las especies de Coryphantha con base en 11 caracteres cualitativos. IA, grupo de especies de Coryphantha sin glándulas extraflorales. IB, grupo de especies de Coryphantha con glándulas extraflorales.

y $C$. retusa no desarrollan espinas centrales, mientras que en $C$. compacta, $C$. durangensis, C. gracilis, C. greenwoodii, C. pallida y C. radian pueden estar presente o ausente en individuos de una población o entre poblaciones. La espina central recta domina entre las especies con 55\% (21). La forma curvada está presente en 14 especies (37\%) y la forma ganchuda en dos, C. delicata y $C$. hintoniorum. El color pardo es dominante en las espinas centrales con 47\% (18 

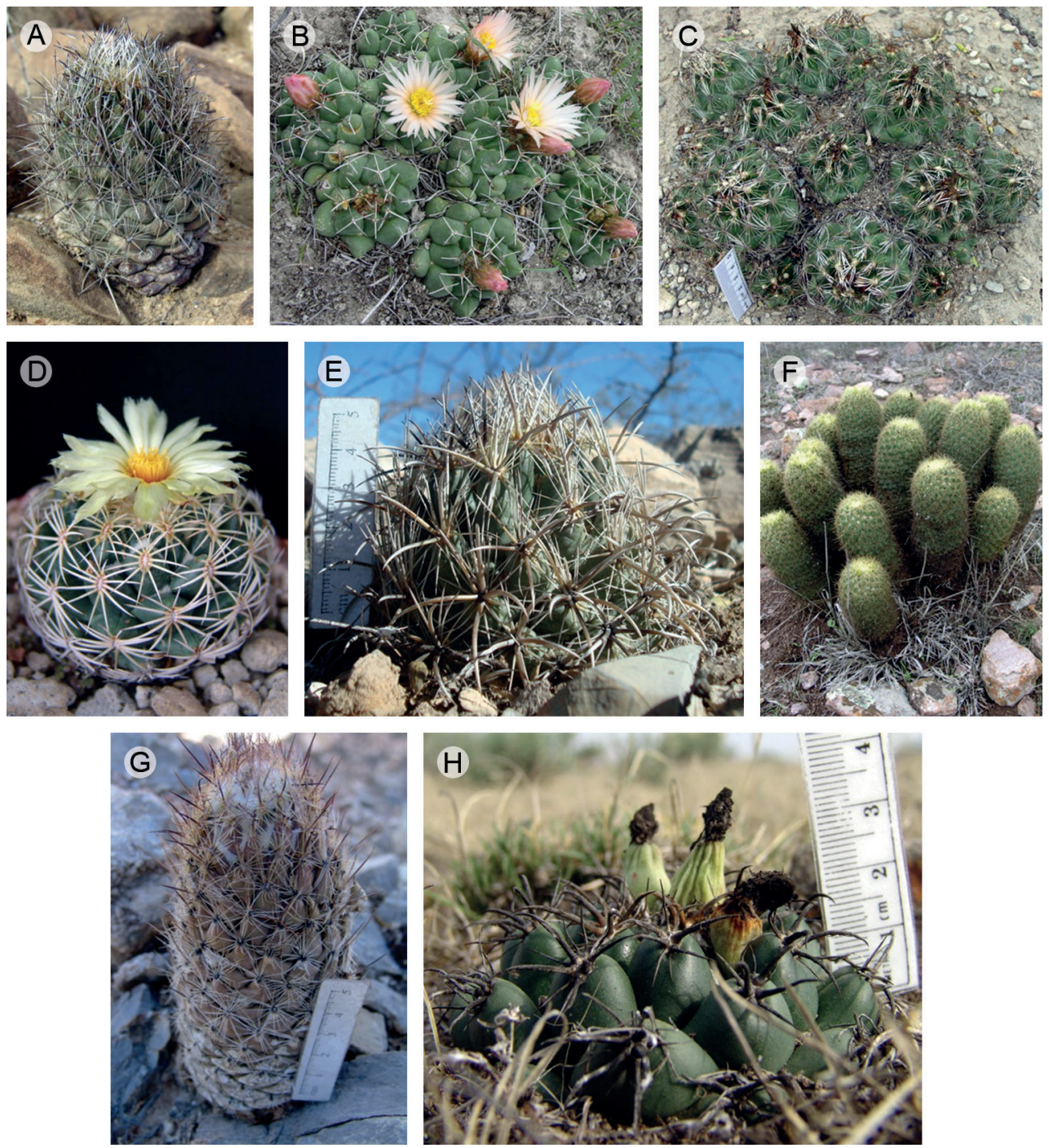

Fig. 2. Caracteres cualitativos de Coryphantha. Tipo de crecimiento: A. solitario ( $C$. salinensis); B. ramificado (C. maiz-tablasensis); C. agrupado (C. nickelsiae). Forma del tallo; D. globosa (C. retusa); E. ovoide (C. kracikii); F. cilíndrica (C. erecta); G. cilíndrica ovoide (C. durangensis); H. globosa deprimida (C. pycnacantha). 

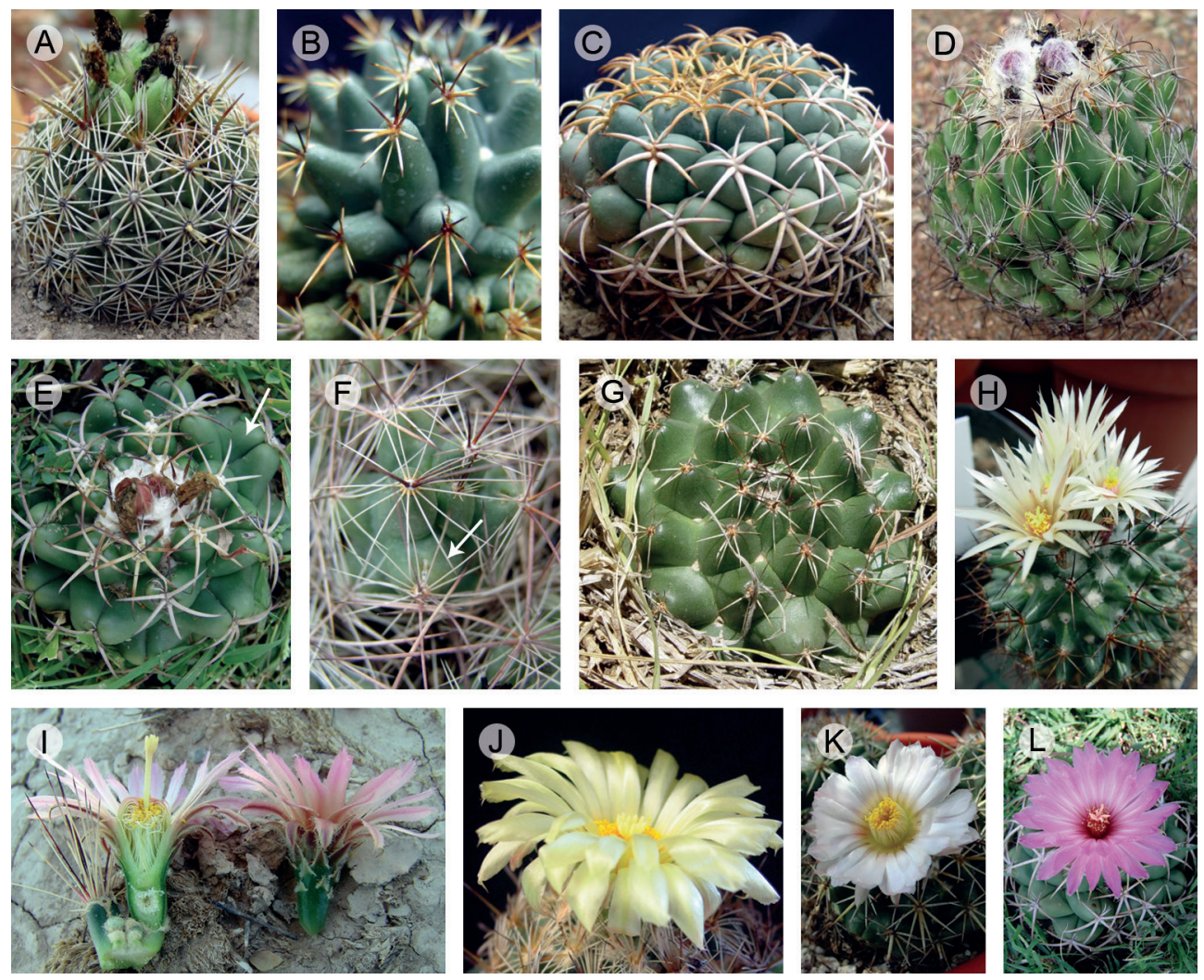

Fig. 3. Caracteres cualitativos de Coryphantha. Forma del tubérculo. A. cónica; B. cilíndrica; C. gibosa; D. cónica deltoide; E. surco completo; F. surco incompleto; G. sin surco; H. glándulas extraflorales; I. tépalos con margen fimbriado; J. flores de color amarillento; K. flores de color blanquecino; L. flores de color magenta.

especies), seguido por el blanquecino con 29\% (11). Con menor frecuencia se encuentran el color pardo amarillento (seis), el negro y el gris en dos especies respectivamente. El 79\% (38) poseen espinas radiales de color blanquecino y el resto de las especies tienen espinas radiales pardas o pardo amarillentas. Excepto en Coryphantha macromeris donde el margen de los tépalos es fimbriado (Fig. 3I), el margen es entero en todas las especies. El 60\% (29) tiene flores de color amarillento (Fig. 3J) con tonos de coloración variables entre pálidos a saturados. El 25\% presenta flores blanquecinas a ligeramente rosadas (Fig. 3K) o de color amarillento pálido. Solo $8 \%$ de las especies (cuatro) poseen flores de color magenta (Fig. 3L) y en 6\% las flores son de color anaranjado pálido. 
Caracteres morfométricos para especies sin glándulas

El análisis de conglomerados (AC) ejecutado con 17 variables cuantitativas para las especies sin glándulas extraflorales (subgrupo IA) generó tres grupos, de los cuales el representado por Coryphantha radians está integrado por 16 especies, el grupo C. sulcata por 13 y el grupo C. elephantidens por solo tres (Fig. 4A). El ACP para el grupo sin glándulas generó cinco componentes principales con eigenvalores iguales o mayores a 1.0, los cuales en total sumaron $80.55 \%$ de la variación. El componente uno aportó $33.19 \%$ de la variación y separa al grupo C. elephantidens por el ancho del tubérculo (0.4035), el largo de la areola (0.3522) y la longitud del surco (0.3513). Los grupos C. radians y C. sulcata se distinguen parcialmente por el componente dos que explica $18.36 \%$ de la variación. Los caracteres de mayor peso en este componente fueron el grosor de las espinas centrales (0.5033), el número de espinas centrales $(0.4730)$ y la longitud de las espinas centrales $(0.4464)$. En el $\mathrm{AD}$ del grupo C. radians, las primeras tres funciones discriminantes aportan 35.00, 21.22 y $12.97 \%$ de la variación respectivamente y explican $69.19 \%$ de la variación total. Las correlaciones entre las variables discriminantes y los coeficientes de las funciones lineales discriminantes son mostradas en el Cuadro 2. En la primera función los pesos discriminantes mayores corresponden al largo del fruto que muestra una correlación negativa, la altura del tallo y el número de espinas centrales ambos caracteres con una correlación positiva. La segunda está positivamente correlacionada con el número de espinas radiales y el largo de la areola y tiene una correlación negativa con el largo del tubérculo. La tercera está correlacionada positivamente con el largo del fruto, grosor de las espinas centrales y número de espinas radiales (Cuadro 2).

Se obtuvieron 12 funciones discriminantes, estadísticamente significativas $(\mathrm{P}<0.05)$, a un nivel de confianza de $95 \%$ (Cuadro 2). La primera función discrimina a Coryphantha cuencamensis, C. longicornis, C. pseudoechinus, C. pulleineana y C. recurvata de las demás especies que forman el grupo $C$. radians. La segunda distingue a $C$. delicata, C. hintoniorum, C. longicornis, C. maiz-tablasensis y $C$. pseudonickelsiae de las otras especies del grupo (Fig. 5A), mientras que la tercera función segrega a $C$. delicata y C. maiz-tablasensis. Se registró 96.84\% (Cuadro 3 ) de casos correctamente clasificados. Un espécimen de $C$. durangensis fue clasificado como $C$. cuencamensis y uno de $C$. pseudoradians fue clasificado como $C$. compacta y otro más en $C$. delicata.

En el AD del grupo Coryphantha sulcata, las tres primeras funciones discriminantes contribuyeron con $37.89,21.73$ y $14.31 \%$ de la variación respectivamente y en conjunto explican el $73.93 \%$ de la variación total. En la primera función los pesos 
A

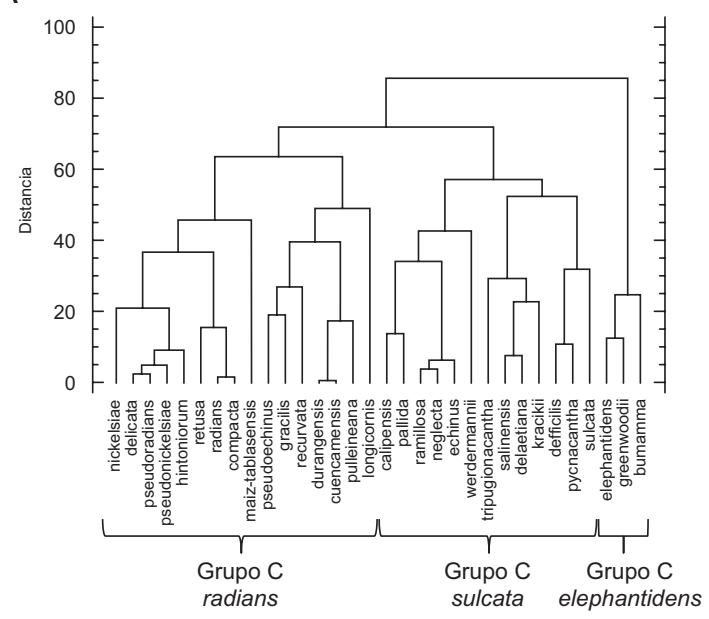

B Metodo de Ward, distancia Euclideana
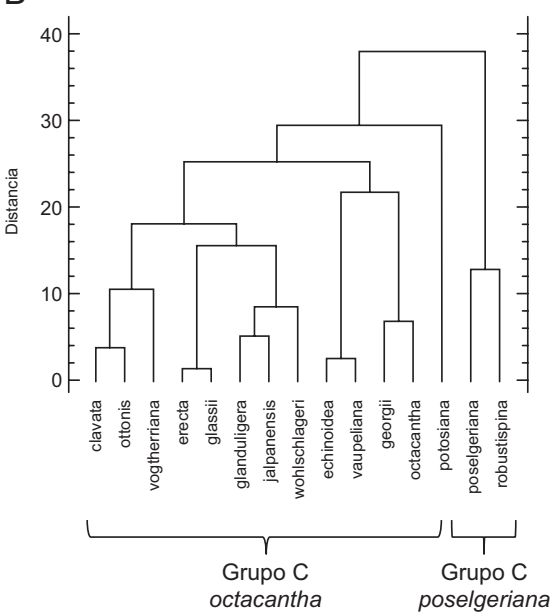

Fig. 4. Agrupamientos de especies. A. sin glándulas; B. con glándulas.

A Gráfica de funciones discriminantes

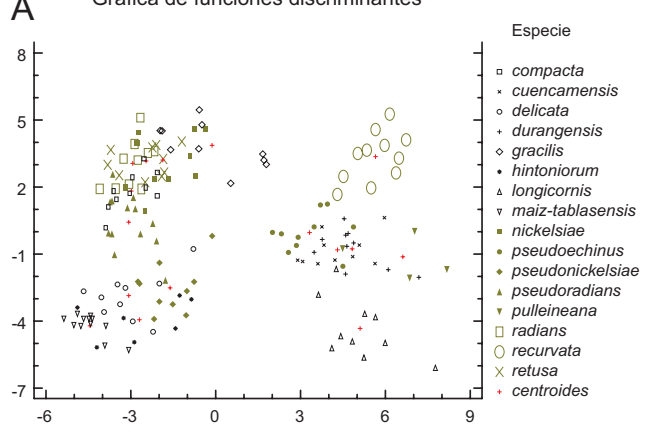

C Gráfica de funciones discriminantes

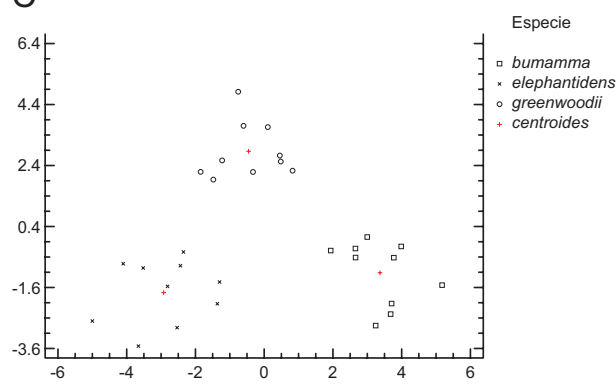

B Gráfica de funciones discriminantes
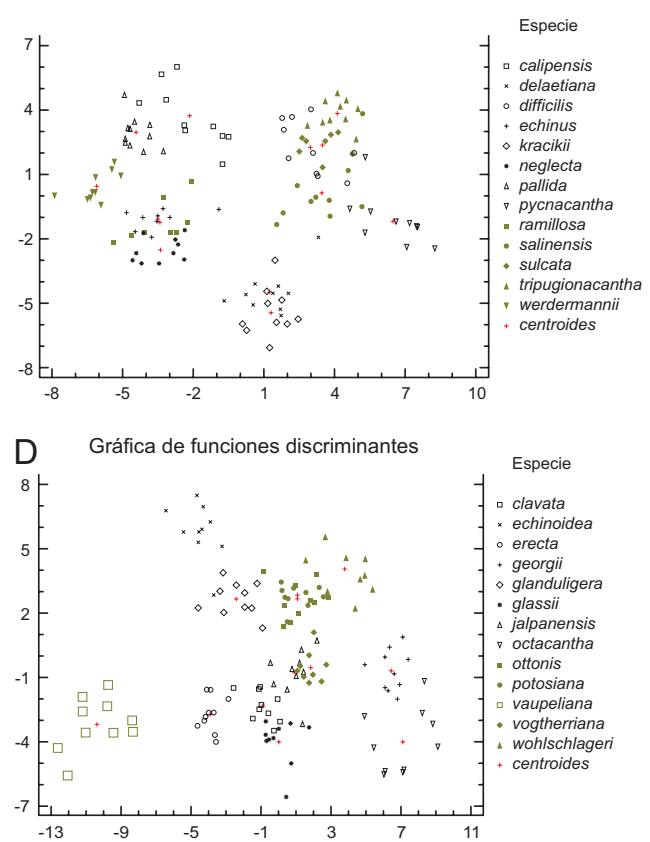

Fig. 5. Gráficos del análisis discriminante. A. grupo C. radians; B. grupo C. sulcata; C. grupo C. elephantidens; D. grupo C. octacantha. 
Cuadro 2. Relación entre las variables discriminantes y los coeficientes de la función lineal discriminante en el grupo Coryphantha radians. En negritas los caracteres por función con mayor peso.

\begin{tabular}{lrrrrr}
\hline Carácter & Función 1 & Función 2 & Función 3 & Función 4 & Función 5 \\
\hline Altura tallo & $\mathbf{0 . 5 8 8 3 9 8}$ & -0.103862 & 0.00263216 & -0.0238348 & $\mathbf{0 . 7 3 7 4 5 2}$ \\
Diámetro tallo & -0.157706 & -0.142937 & -0.21117 & $\mathbf{- 0 . 9 6 6 0 9}$ & $\mathbf{- 0 . 8 2 9 6 4 5}$ \\
Largo del tubérculo & 0.206549 & $\mathbf{- 0 . 6 1 0 2 6}$ & -0.204371 & -0.315031 & -0.100778 \\
Ancho tubérculo & -0.200699 & 0.380091 & -0.0588294 & 0.325548 & 0.281444 \\
Largo areola & 0.170533 & $\mathbf{0 . 4 7 0 2 9 1}$ & 0.25506 & $\mathbf{- 0 . 7 6 5 4 9 9}$ & -0.0043554 \\
Ancho tubérculo & -0.044605 & -0.451617 & 0.22673 & $\mathbf{0 . 6 7 3 3 1 2}$ & 0.424208 \\
Long surco & -0.262508 & 0.282885 & 0.122345 & 0.424386 & -0.239973 \\
Núm. espinas radiales & 0.157328 & $\mathbf{0 . 6 8 5 0 6}$ & $\mathbf{0 . 4 9 8 2 6 2}$ & 0.228345 & 0.188808 \\
Núm. espinas centrales & $\mathbf{0 . 3 9 8 8 7 9}$ & -0.0219739 & -0.0250937 & 0.200643 & $\mathbf{0 . 6 2 0 0 6 2}$ \\
Long. espinas radiales & -0.317538 & 0.357555 & 0.425143 & 0.379436 & -0.29837 \\
Long. espinas centrales & 0.255323 & -0.225698 & -0.025735 & -0.363016 & -0.313304 \\
Largo flor & -0.107287 & 0.262818 & -0.0939906 & 0.175282 & 0.136726 \\
Ancho flor & -0.0124445 & -0.284345 & 0.116201 & 0.123735 & 0.246347 \\
Largo fruto & $\mathbf{0 . 5 9 5 6 5 6}$ & -0.537506 & $\mathbf{0 . 5 7 1 8 4 9}$ & -0.309595 & 0.170892 \\
Ancho fruto & -0.130575 & 0.512521 & -0.206821 & -0.0367393 & 0.387256 \\
Grosor espinas radiales & 0.198579 & 0.126412 & -0.49276 & 0.0263106 & 0.591519 \\
Grosor espinas centrales & 0.0118802 & -0.328603 & $\mathbf{0 . 5 3 0 4 4 4}$ & 0.0671619 & -0.335694 \\
Porcentaje de variación & $\mathbf{3 5 . 0 0}$ & $\mathbf{2 1 . 2 2}$ & $\mathbf{1 2 . 9 7}$ & $\mathbf{9 . 6 6}$ & $\mathbf{6 . 6 7}$ \\
Lambda de Wilks & $\mathbf{0 . 0 0 0 0 1 3 1 3}$ & $\mathbf{0 . 0 0 0 1 3 2 4}$ & $\mathbf{0 . 0 0 0 8 6 7 3}$ & $\mathbf{0 . 0 0 4 4 5 0}$ & $\mathbf{0 . 0 1 7 1 5}$ \\
Chi-Cuadrada & $\mathbf{1 5 7 9 . 1 0 3 0}$ & $\mathbf{1 2 5 4 . 5 3 8 6}$ & $\mathbf{9 9 0 . 5 2 9 5}$ & $\mathbf{7 6 0 . 7 7 1 7}$ & $\mathbf{5 7 1 . 2 2 1 5}$ \\
GL & $\mathbf{2 2 4}$ & $\mathbf{1 9 5}$ & $\mathbf{1 6 8}$ & $\mathbf{1 4 3}$ & $\mathbf{1 2 0}$ \\
Valor-P & $\mathbf{0 . 0 0 0 0}$ & $\mathbf{0 . 0 0 0}$ & $\mathbf{0 . 0 0 0}$ & $\mathbf{0 . 0 0 0 0}$ & $\mathbf{0 . 0 0 0 0}$ \\
\hline & & & & &
\end{tabular}

Cuadro 3. Relación de porcentajes de clasificación correcta por grupos.

\begin{tabular}{lc}
\hline Grupo & $\begin{array}{c}\text { Porcentaje de } \\
\text { clasificación correcta }\end{array}$ \\
\hline C. radians & 96.84 \\
C. sulcata & 96.83 \\
C. elephantidens & 100 \\
C. octacantha & 100 \\
C. poselgeriana & 100 \\
\hline
\end{tabular}


discriminantes mayores correspondieron al número de espinas radiales y ancho de la flor, ambos correlacionados negativamente con la función y el número de espinas centrales con correlación positiva. La segunda está correlacionada positivamente con el ancho de la flor y el largo del tubérculo y negativamente con la longitud de las espinas radiales. La tercera tiene correlación positiva con el largo del fruto y el número de espinas centrales y negativa con el largo del tubérculo (Cuadro 4).

Se obtuvieron 10 funciones discriminantes estadísticamente significativas $(\mathrm{P}<0.05)$ a un nivel de confianza de $95 \%$ (Cuadro 4). La primera discrimina a Coryphantha calipensis, C. echinus, C. neglecta, C. pallida, C. ramillosa y C. werdermannii de C. difficilis, C. pycnacantha, C. salinensis, C. sulcata y C. tripugionacantha (Fig. 5B). La segunda diferencia a $C$. delaetiana y $C$. kracikii, mientras que la tercera separa a C. kracikii y C. werdermannii de las otras especies del grupo. Se registró 96.83\% (Cuadro 3) de casos correctamente clasificados. Un ejemplar de $C$. neglecta fue clasificado como C. ramillosa y tres ejemplares de C. ramillosa fueron clasificados como C. echinus.

Para el grupo Coryphantha elephantidens, la primera y segunda función aportan 61.74 y $38.26 \%$ de la variación respectivamente. Las variables con mayor peso en la primera función son el diámetro del tallo (0.8003), el ancho de la flor $(-0.7268)$ y la longitud del surco (-0.6153). Esta función discriminante diferencia a C. bumamma de C. elephantidens (Fig. 5C). En la segunda función destacan las variables longitud del surco (0.6281), longitud de las espinas radiales (0.5710) y largo del fruto (-0.5200). Esta función discrimina a C. greenwoodii de C. bumamma y $C$. elephantidens. (Fig. 5C). Se obtuvieron dos funciones discriminantes estadísticamente significativas $(\mathrm{P}<0.05)$ a un nivel de confianza de $95 \%$. Se registró $100 \%$ (Cuadro 3) de los casos correctamente clasificados.

Caracteres morfométricos para especies con glándulas

Para el grupo con glándulas se obtuvieron cuatro componentes principales en el ACP cuyos eigenvalores fueron iguales o mayores a 1.0 y acumularon $88.95 \%$ de la variación. El primero de los componentes principales aportó $55.27 \%$ de la misma y las variables que explican la delimitación del grupo Coryphantha octacantha (13 especies) y del grupo C. poselgeriana (dos especies) son la longitud de las espinas centrales (0.3029), el largo del fruto (0.2989) y el ancho del fruto (0.2909). Las tres primeras funciones discriminantes para el grupo Coryphantha octacantha participaron con $43.43,21.27$ y $13.33 \%$ de la variación respectivamente y sumaron un total de $78.03 \%$ (Cuadro 5). Las variables con mayor peso en la primera función son el número de espinas radiales correlacionada negativamente, el largo de la flor y el lar- 
Cuadro 4. Relación entre las variables discriminantes y los coeficientes de la función lineal discriminante en el grupo Coryphantha sulcata. En negritas los caracteres por función con mayor peso.

\begin{tabular}{lrrrrr}
\hline Carácter & Función 1 & Función 2 & Función 3 & Función 4 & Función 5 \\
\hline Altura tallo & 0.058170 & -0.235022 & -0.004888 & -0.042665 & -0.370559 \\
Diámetro tallo & -0.26877 & 0.278756 & -0.074521 & $\mathbf{- 0 . 4 4 3 7 5 8}$ & 0.19057 \\
Largo tubérculo & 0.18055 & $\mathbf{0 . 4 0 8 2 4 2}$ & $\mathbf{- 0 . 5 2 3 4 7 9}$ & 0.093184 & 0.333469 \\
Ancho tubérculo & -0.17109 & -0.055844 & -0.081170 & 0.116372 & 0.0477696 \\
Largo areola & 0.033192 & 0.11797 & -0.010892 & 0.074554 & -0.018439 \\
Ancho areola & 0.338139 & -0.034317 & 0.0289502 & 0.36189 & -0.086561 \\
Long surco & 0.351473 & 0.123305 & -0.292489 & $\mathbf{0 . 6 2 5 4 2 8}$ & 0.078317 \\
Núm. espinas radiales & $\mathbf{- 0 . 7 1 4 1 8 5}$ & -0.274913 & -0.177342 & 0.037705 & -0.051647 \\
Núm. espinas centrales & $\mathbf{0 . 5 8 6 5}$ & -0.127026 & $\mathbf{0 . 4 8 9 7 3 1}$ & 0.204076 & $\mathbf{0 . 4 6 9 4 9 9}$ \\
Long. espinas radiales & -0.254045 & $\mathbf{- 0 . 6 3 8 2 2 1}$ & 0.0858746 & $\mathbf{0 . 4 1 9 7 3 8}$ & $\mathbf{- 0 . 5 2 3 1 8 1}$ \\
Long. espinas centrales & -0.096937 & -0.305459 & 0.211158 & -0.269586 & 0.133737 \\
Grosor espinas radiales & 0.241535 & 0.315663 & 0.108498 & -0.420771 & $-\mathbf{0 . 5 9 2 0 7 9}$ \\
Grosor espinas centrales & 0.151443 & 0.260103 & 0.252867 & 0.263763 & -0.196283 \\
Largo flor & -0.340097 & 0.288179 & 0.325778 & 0.183731 & -0.106163 \\
Ancho flor & $\mathbf{0 . 5 5 5 7 8 8}$ & $\mathbf{0 . 4 6 2 2 6 3}$ & 0.103509 & 0.38628 & -0.056629 \\
Largo fruto & -0.241229 & -0.146243 & $\mathbf{0 . 6 0 5 0 6 6}$ & 0.276142 & 0.0057914 \\
Ancho fruto & 0.099128 & 0.080399 & -0.016831 & -0.019450 & 0.101746 \\
Porcentaje de variación & 37.89 & 21.73 & 14.31 & 8.38 & 6.49 \\
Lambda de Wilks & 0.000001 & 0.00002663 & 0.00028022 & 0.00203724 & 0.00951698 \\
Chi-Cuadrada & 1478.182 & 1158.679 & 899.7910 & 681.5773 & 512.0145 \\
GL & 204 & 176 & 150 & 126 & 104 \\
Valor-P & 0.0000 & 0.0000 & 0.000 & 0.0000 & 0.0000 \\
\hline & & & & &
\end{tabular}

go del tubérculo correlacionadas positivamente. En la segunda los pesos discriminantes mayores pertenecen a la altura del tallo, diámetro del tallo y el largo del fruto. Las variables con mayor peso en la tercera fueron la longitud de las espinas radiales correlacionada positivamente, la altura del tallo y el número de espinas radiales con correlación positiva (Cuadro 5).

Se obtuvieron 12 funciones discriminantes estadísticamente significativas $(\mathrm{P}<0.05)$ (Cuadro 5). La primera función discrimina a Coryphantha potosiana de $C$. georgii y C. octacantha. (Fig. 5D). La segunda función diferencia al grupo de C. clavata, C. erecta, C. georgii, C. glassii, C. jalpanensis, C. octacantha, C. potosiana y 
Cuadro 5. Relación entre las variables discriminantes y los coeficientes de la función lineal discriminante en el grupo Coryphantha octacantha. En negritas los caracteres por función con mayor peso

\begin{tabular}{lrrrrr}
\hline Carácter & Función 1 & Función 2 & Función 3 & Función 4 & Función 5 \\
\hline Altura tallo & -0.0629191 & $\mathbf{- 0 . 5 4 5 5 5 7}$ & $\mathbf{- 0 . 6 1 0 2 4 4}$ & -0.0448479 & -0.130179 \\
Diámetro tallo & 0.189373 & $\mathbf{- 0 . 4 9 0 3 8 6}$ & 0.321727 & $\mathbf{- 0 . 4 6 3 4 4}$ & -0.044559 \\
Largo tubérculo & $\mathbf{0 . 6 1 2 4 9 7}$ & -0.202344 & -0.293928 & $\mathbf{0 . 8 6 0 8 4 1}$ & 0.130644 \\
Ancho tubérculo & -0.40356 & 0.195455 & 0.0838847 & 0.359518 & -0.142411 \\
Largo areola & -0.480367 & 0.195608 & -0.42972 & -0.101685 & $\mathbf{- 0 . 5 9 4 7 9 6}$ \\
Ancho areola & 0.159596 & -0.0293 & 0.281327 & $\mathbf{- 0 . 5 9 0 2 3 3}$ & 1.29894 \\
Long surco & 0.16431 & -0.182177 & -0.203438 & -0.129231 & $\mathbf{- 0 . 4 9 3 5 6 7}$ \\
Núm. espinas radiales & $\mathbf{- 0 . 9 0 5 8 8 2}$ & 0.287794 & $\mathbf{- 0 . 5 3 4 3 9}$ & 0.092658 & -0.0388754 \\
Núm. espinas centrales & 0.452155 & 0.285139 & -0.170278 & 0.34899 & -0.138891 \\
Long. espinas radiales & 0.033965 & 0.247748 & $\mathbf{0 . 6 9 1 6 1 2}$ & 0.262244 & -0.465206 \\
Long. espinas centrales & -0.00655866 & -0.0122802 & -0.384667 & -0.334005 & 0.0718141 \\
Grosor espinas radiales & 0.096931 & 0.344929 & -0.102339 & -0.284506 & 0.121209 \\
Grosor espinas centrales & 0.0134174 & 0.199878 & -0.115673 & -0.11244 & -0.0872451 \\
Largo flor & $\mathbf{0 . 6 1 5 5 8 8}$ & 0.245251 & -0.183641 & 0.0901179 & 0.0750916 \\
Ancho flor & 0.0398365 & 0.371429 & -0.0878509 & 0.117593 & -0.0864054 \\
Largo fruto & 0.237817 & $\mathbf{0 . 4 7 7 0 0 4}$ & 0.0270416 & -0.391174 & $\mathbf{- 0 . 5 8 8 6 2 8}$ \\
Ancho fruto & 0.198162 & -0.0190864 & -0.00973141 & -0.252717 & 0.448125 \\
Porcentaje de variación & $\mathbf{4 3 . 4 3}$ & $\mathbf{2 1 . 2 7}$ & $\mathbf{1 3 . 3 3}$ & $\mathbf{7 . 9 3}$ & $\mathbf{5 . 5 0}$ \\
Lambda Wilks & $\mathbf{0 . 0 0 0 0 2 2 3 2}$ & $\mathbf{0 . 0 0 0 2 6 8 1}$ & $\mathbf{0 . 0 0 2 1 1 8 7 2}$ & $\mathbf{0 . 1 0 8 1 0 9}$ & $\mathbf{0 . 0 4 1 5 8 0 8}$ \\
Chi-Cuadrada & $\mathbf{1 2 2 0 . 9 0 7 4}$ & $\mathbf{9 3 7 . 5 4 7 4}$ & $\mathbf{7 0 1 . 8 9 1 4}$ & $\mathbf{5 1 6 . 1 0 1 4}$ & $\mathbf{3 6 2 . 5 3 3 4}$ \\
GL & $\mathbf{1 7 6}$ & $\mathbf{1 5 0}$ & $\mathbf{1 2 6}$ & $\mathbf{1 0 4}$ & $\mathbf{8 4}$ \\
Valor-P & $\mathbf{0 . 0 0 0 0}$ & $\mathbf{0 . 0 0 0 0}$ & $\mathbf{0 . 0 0 0 0}$ & $\mathbf{0 . 0 0 0 0}$ & $\mathbf{0 . 0 0 0 0}$ \\
\hline & & & & &
\end{tabular}

C. vogtherriana de C. echinoidea, C. glanduligera, C. ottonis, C. vaupeliana y C. wohlschlageri (Fig. 5D). La tercera función discriminante separa a $C$. vogtherriana de $C$. octacantha. Se registró el total (Cuadro 3) de casos correctamente clasificados.

En el grupo Coryphantha poselgeriana se encontró una función discriminante estadísticamente significativa ( 1 de Wilks $=0.001774$, Valor-P $=0.0000)$ a un nivel de significancia de 95\%. Los coeficientes de mayor peso son el diámetro del tallo (17.284) correlacionado positivamente con la función, la altura del tallo (-13.6517) y la longitud de las espinas centrales (-8.39702) con correlación negativa (datos no mostrados). Se registró el total (Cuadro 3) de los casos correctamente clasificados. 


\section{DISCUSIÓN}

Caracteres cualitativos

Los agrupamientos formados a partir de niveles de similitud de caracteres cualitativos (Fig. 1) fueron distintos a los obtenidos mediante el análisis de variación morfológica con los cuantitativos (Figs. 4A y 4B). La cuantificación de los datos permite ejecutar numerosos métodos estadísticos cuyos resultados aportan elementos estables para la clasificación de Coryphantha. Tradicionalmente se han empleado caracteres cualitativos para el reconocimiento de especies de Coryphantha (Zimmerman, 1985; Bravo-Hollis y Sánchez-Mejorada, 1991; Dicht y Lüthy, 2001); sin embargo, la naturaleza de estos datos impide establecer patrones de comportamiento entre las especies.

Las especies del grupo IA (Fig. 1) no desarrollan glándulas extraflorales en la madurez o durante la floración. Este agrupamiento concuerda con la serie Aulacothelae propuesta por Bravo-Hollis y Sánchez-Mejorada (1991) y con el subgénero Coryphantha de Dicht y Lüthy (2001). El grupo IB representa a las especies que desarrollan en la etapa reproductiva glándulas extraflorales en la cara adaxial del tubérculo. Este conjunto coincide con la serie Glanduliferae de Bravo-Hollis y Sánchez-Mejorada (1991) y con el subgénero Neocoryphantha de Dicht y Lüthy (2001). En general, esos nectarios permanecen de forma constante aunque menos turgentes a lo largo del desarrollo de la planta. Sin embargo, en C. poselgeriana y C. robustispina son visibles solo durante la floración y posteriormente quedan ocultas por tricomas. El conocimiento sobre la función de este tipo de nectarios en Coryphantha no ha sido abordado, pero observaciones indican una actividad estacional, volviéndose más turgentes durante los eventos de floración y fructificación (Vázquez, obs. pers.). Se ha considerado que estos nectarios participan como elementos para atraer hormigas defensoras contra insectos fitófagos (Buffa et al., 2009; Rudall, 2009). La disminución de predadores de las estructuras reproductoras está relacionada con el incremento de la capacidad reproductiva (Pickett y Clark, 1979).

Bravo-Hollis y Sánchez-Mejorada (1991) erigieron la serie Macromeres para ubicar a Coryphantha macromeris. Dicht y Lüthy (2001) colocan a esta especie en la sección monotípica Lepidocoryphantha perteneciente al subgénero Neocoryphantha. Los resultados obtenidos en este estudio colocan a C. macromeris como la más disimilar en su morfología, tal lo indica la longitud de la rama que conecta esta terminal (Fig. 1). Por lo tanto, debe considerarse la hipótesis de su exclusión del género Coryphantha según lo sugieren los resultados recientes del análisis filogenético de la tribu Cacteae (Vázquez-Sánchez et al., 2013), o bien no pertenece al núcleo de Coryphantha (Bárcenas et al., 2011). 
Caracteres morfométricos para especies sin glándulas

Las relaciones entre especies obtenidas en este estudio, en general, no concuerdan con la clasificación morfológica de Dicht y Lüthy (2001). El agrupamiento de Coryphantha bumamma, C. elephantidens y C. greenwoodii (Fig. 4A) concuerda pro parte con la serie Retusae (incluyendo C. retusa), cuyo carácter diagnóstico es el tubérculo con un ancho en la base mayor a $0.7 \mathrm{~cm}$ (Dicht y Lüthy, 2001, 2005a). El ACP indicó que el primer componente segrega a estas especies por el ancho del tubérculo, el largo de la areola y la longitud del surco. Otros caracteres que contribuyen a definirlo son los tubérculos gibosos y la ausencia de espinas centrales. Dicht y Lüthy (2005b) consideraron que la diferencia entre $C$. elephantidens y $C$. bumamma y C. greenwoodii es el tipo de crecimiento solitario (C. elephantidens) versus agrupado (C. bumamma y $C$. greenwoodii). Nuestros resultados muestran que predomina el crecimiento solitario en los tres taxa y rara vez se ramifican o agrupan. Los caracteres cualitativos (Fig. 1) establecieron diferencias entre estos taxa y el AD proporcionó una clara discriminación (Fig. 5C) entre ellos con base en el ancho del fruto, ancho de la flor, largo del fruto, grosor y longitud de las espinas radiales, altura y diámetro del tallo y largo de la areola que justifica su designación en la categoría de especies.

Es complicado establecer caracteres diagnósticos que precisen las diferencias entre los grupos Coryphantha radians y C. sulcata (Fig. 4A). El componente dos del ACP separa a ambos con base en el grosor de espinas centrales (0.05033), el número de ellas (0.4730) y la longitud de las mismas (0.4464). Sin embargo, en el ACP resultó difícil constreñir a C. pycnacantha. Las especies del grupo C. radians están incluidas en tres series de Dicht y Lüthy (2001) establecidas con base en caracteres relacionados a la forma de los tubérculos. Coryphantha kracikii y $C$. salinensis son especies que persisten en los agrupamientos de los AC con variables cualitativas y cuantitativas. Ambas están contenidas en la serie Salinensis propuesta por Dicht y Lüthy (2001). Las funciones discriminantes circunscriben sin dificultad a la mayoría de las especies del grupo C. radians. Sin embargo, no son convincentes las delimitaciones entre $C$. cuencamensis y $C$. durangensis, quienes manifiestan parecido morfométrico (Fig. 4A y 5A) y sus diferencias están soportadas en variaciones en el color de las espinas centrales, radiales y de la flor. Dicht y Lüthy (2005a) situaron al primer taxón como subespecie de $C$. durangensis, disposición con la cual concordamos. Coryphantha compacta y $C$. radians son bastante semejantes en su morfometría (Fig. 4A y 5A), aunque $C$. compacta raramente presenta una espina central independiente de su estado de desarrollo, en tanto que $C$. radians puede formar una espina central en alguna etapa de su desarrollo o permanecer sin 
ella. La demarcación de C. delicata, C. hintoniorum y C. pseudonickelsiae no fue posible con variables cuantitativas (Fig. 5A). Coryphantha hintoniorum muestra una mayor variación morfológica en los caracteres cuantitativos y no llega a tener más de 15 espinas radiales, la forma de los tubérculos es cilíndrica y sus flores son de color blanquecino. En cambio, C. delicata rara vez exhibe menos de 17 espinas radiales, tubérculos cónicos y desarrolla flores amarillentas. El parecido entre ambas especies radica en que presentan una sola espina central ganchuda y blanquecina. Coryphantha pseudonickelsiae tiene una espina central curvada, de color pardo obscuro, flores de color amarillento pálido a blanquecinas y se distribuye en Chihuahua y Durango, mientras que $C$. delicata tiene flores de color amarillento saturado y su distribución abarca los estados de Coahuila, Nuevo León, San Luis Potosí, Tamaulipas y Zacatecas.

El grupo Coryphantha sulcata incluye especies que por su variación morfológica están contenidas en cuatro series de acuerdo con Dicht y Lüthy (2001). El AD demarca a la mayoría de las especies del grupo con excepción de $C$. difficilis, $C$. ramillosa y $C$. sulcata. Las diferentes funciones discriminantes agrupan a $C$. difficilis con C. sulcata y C. tripugionacantha. Estas especies pueden reconocerse por la forma del tallo, la forma y color de los tubérculos. En particular C. tripugionacantha presenta de manera constante tres espinas centrales adpresas al tubérculo, un rasgo que no desarrolla $C$. difficilis.

Aunque Coryphantha difficilis no se agrupa con C. salinensis en el AC cualitativo (Fig. 1), están organizados en el mismo conjunto en el AC cuantitativo (Fig. 4A). Por su parecido morfométrico es difícil delimitar ambas especies con las diferentes funciones discriminantes (Fig. 5B). Los ejemplares de estas especies se dispersan y alejan en distintas direcciones con diferentes funciones discriminantes, indicio de su variación morfológica, especialmente acentuado en C. salinensis. De hecho la morfología de $C$. difficilis de este estudio concuerda notablemente con lo reportado por Dicht y Lüthy (2005a). Al comparar los caracteres descritos por Bravo-Hollis y Sánchez-Mejorada (1991) para C. obscura, C. roederiana y C. speciosa, así como los señalados por Bremer (1980) para C. borwigii, encontramos notable congruencia con los caracteres incluidos en los protólogos de C. roederiana, C. speciosa y C. obscura (Boedeker, 1929, 1930a 1930b). La falta de diferencias marcadas entre ellas condujo a Zimmerman (1985) a considerar que C. borwigii, C. obscura, C. roederiana y C. speciosa son sinónimos de C. salinensis. Nuestros resultados son congruentes con esta última propuesta.

La localidad tipo de Coryphantha difficilis es desconocida; sin embargo, los datos morfológicos y el archivo de imágenes de nuestro estudio concuerdan con la 
descripción e imagen del protólogo (Quehl, 1908). La distribución geográfica de $C$. salinensis según Dicht y Lüthy (2005a) corresponde a las localidades de Nuevo León y Tamaulipas y la de $C$. difficilis a Coahuila, pero González (2004) establece una distribución amplia de $C$. difficilis en el noroeste de Nuevo León y una distribución restringida para $C$. salinensis que se traslapa con $C$. difficilis. Por el estrecho parecido morfológico entre $C$. difficilis y $C$. salinensis consideramos que $C$. difficilis debe tratarse como subespecie de $C$. salinensis.

Coryphantha kracikii no presenta la variación morfológica de $C$. difficilis y $C$. salinensis. Los ejemplares examinados mostraron intervalos de variación estrechos a constantes en altura y diámetro del tallo, número de espinas centrales y radiales, longitud de las espinas centrales, forma del tallo y distribución densa de las espinas en todo el tallo. Las flores presentan garganta rojiza por lo que es más parecida a $C$. salinensis y no a $C$. difficilis como observó Hunt (2006). Por su parte, $C$. ramillosa generalmente aparece asociada a $C$. echinus en gráficas obtenidas con distintas funciones discriminantes. Sin embargo, se distinguen entre sí por el color de las espinas radiales, la longitud de la espina central y el color de la flor. Mientras tanto, C. werdermannii se definió en el AD y presenta un patrón de desarrollo exclusivo. Los organismos jóvenes no presentan espinas centrales. Una vez que llegan a la etapa reproductiva, pueden tener dos aspectos, uno que consiste en que una tercera parte del tallo desarrolle espinas centrales y el otro en que todo el tallo las presente. No se conoce si ambos aspectos corresponden a etapas lineales de crecimiento y si se suceden una a otra o si son formas de desarrollo no secuenciales. A pesar de que Dicht y Lüthy (2005a) indican en la descripción de C. calipensis que existen al menos cinco estados de carácter distintos entre $C$. calipensis y $C$. pallida, colocan a $C$. calipensis como una subespecie de $C$. pallida. En la misma descripción señalan que $C$. calipensis forma grupos por rebrotes, pero nuestras observaciones indican que estos agrupamientos no son ramificaciones o rebrotes sino colonias de organismos independientes que se desarrollaron en torno a una planta progenitora por efecto específico de la dispersión de semillas. La forma cónico deltoide de los tubérculos de C. calipensis apoya la retención de semillas una vez que inicia el proceso de dispersión. Esta situación no se presenta en $C$. pallida porque la forma de sus tubérculos es distinta. Consideramos que existen suficientes rasgos distintivos entre ambos taxa para reconocerlos como especies diferentes. Coryphantha pulleineana, además de circunscribirse claramente como una especie por sus rasgos cuantitativos, presenta una raíz napiforme cuyas dimensiones de alargamiento no son superadas por C. glanduligera y C. wohlschlageri que también presentan raíces napiformes 
medianamente engrosadas y alargadas. La fisonomía de C. pulleineana es similar a Neolloydia y fue descrita inicialmente por Backeberg (1948) en éste género. Sin embargo, rasgos como el color de la flor, tipo de frutos y semillas condujeron a que Glass (1968) realizara la combinación en Coryphantha.

Caracteres morfométricos para especies con glándulas

El grupo Coryphantha poselgeriana es equivalente a la sección Robustispina de Dicht y Lüthy (2005a). Esta sección se caracteriza por presentar tubérculos de 2 $\mathrm{cm}$ de longitud. En nuestro estudio encontramos que el grupo C. poselgeriana se distingue por el ancho del tubérculo, la longitud del surco y el largo del tubérculo, este último carácter en promedio no alcanza los $2 \mathrm{~cm}$. Las procedencias de los ejemplares de $C$. robustispina evaluados en este estudio, son de cercanías de la región de Baboquivaria, Sonora y corresponden a C. robustispina subsp. robustispina, así como de El Sueco, Chihuahua, que pertenecen a C. robustispina subsp. scheeri de acuerdo con Dicht y Lüthy (2005a). Los ejemplares de ambas procedencias se mantuvieron agrupados en los análisis multivariados, posiblemente debido al traslape de sus rasgos morfológicos. Schmalzel et al. (2004) indicaron que los caracteres empleados para reconocer variedades de C. robustispina propuestos por Benson (1982) se traslapan o corresponden a observaciones incorrectas.

La segunda función discriminante separa notablemente a Coryphantha potosiana porque es la especie que presenta las flores y frutos más pequeños. Zimmerman (1985) colocó a C. echinoidea como sinónimo de C. glanduligera. La segunda función del $\mathrm{AD}$ discrimina una especie de otra por la altura y diámetro del tallo y largo del fruto. Dicht y Lüthy (2005a) mencionan que entre los caracteres que distinguen a $C$. echinoidea de $C$. glanduligera están la forma del tallo globoso y las raíces fibrosas de la primera especie contra el tallo ovoide a clavado y la raíz tuberosa de la segunda, diferencias con las que estamos de acuerdo. Por su parte, C. vaupeliana difícilmente se demarca de $C$. wohlschlageri, aunque esta última tiene mayor número de espinas centrales y flores más grandes, en cambio $C$. vaupeliana tiene frutos más pequeños.

A pesar de que Coryphantha octacantha es la especie que presentó los tallos más altos y los tubérculos con mayor longitud y se circunscribió perfectamente en los $\mathrm{AD}$, es posible confundirla con $C$. georgii debido a que esta especie presenta una marcada variación en la altura del tallo. Dependiendo de las condiciones ecológicas en que crezca puede manifestar formas y alturas del tallo diferentes. Cuando prospera en ambientes abiertos desarrolla una forma globosa deprimida y alturas del tallo de 4 a $5 \mathrm{~cm}$; si lo hace en ambientes sombreados, la forma del tallo se torna 
cilíndrica y alcanza longitudes superiores a los $10 \mathrm{~cm}$. Las variaciones amplias en el número y longitud de espinas radiales y centrales y en las dimensiones de los tubérculos de C. georgii dificultan su separación de $C$. octacantha, aunque rasgos como la coloración verde obscura y la disposición de los tubérculos en el tallo distinguen cualitativamente a C. georgii.

Coryphantha ottonis conjuntamente con C. delaetiana, C. delicata, C. echinus, $C$. elephantidens y $C$. macromeris son las especies con las distribuciones más amplias del género y esa extensa distribución trae aparejada variaciones en los rasgos morfológicos como el tamaño del tallo, tamaño y color de las espinas y de las flores. Zimmerman (1985) incluyó a C. asterias, C. brevimamma, C. bussleri y C. unicornis (en el sentido de Bremer) como sinónimos de C. ottonis; asimismo planteó la posibilidad de que $C$. georgii sea un sinónimo de $C$. ottonis. Hay que señalar que en $C$. ottonis y C. georgii cambia la forma del tallo de acuerdo al ambiente en que se desarrolle, aunque en la forma ovoide o cilíndrica del tallo no alcanza las alturas de C. georgii. Coryphantha clavata no cambia la forma del tallo, de acuerdo al ambiente en que prospera pero el tipo de suelo sí determina la altura del tallo. En leptosoles líticos la altura es de 5 a $10 \mathrm{~cm}$ y en otros suelos alcanza $15 \mathrm{~cm}$ o más. Estas variaciones en el tamaño del tallo asemejan a C. clavata con C. ottonis. Varios aspectos morfométricos de $C$. clavata son similares a $C$. ottonis; el tamaño y color de las flores es diferente entre especies y el largo del fruto de $C$. ottonis es el doble de C. clavata.

Los caracteres cuantitativos no distinguen a Coryphantha glassii de $C$. jalpanensis. Las diferencias en altura y diámetro del tallo, largo y ancho de la flor y del fruto, empleadas en la contrastación de estas especies efectuada por Dicht y Lüthy (2005a) no concuerdan con nuestros resultados. Aunque la altura y el diámetro del tallo fueron en general menores en los ejemplares muestreados de C. jalpanensis, el intervalo de variación se traslapa con C. glassii. Los organismos evaluados de $C$. jalpanensis crecen sobre rocas y estas condiciones limitadas bien pueden impactar en el desarrollo de los ejemplares. Ambas especies comparten rasgos como el tipo de crecimiento ramificado, forma del tallo, forma de la espina central y color de la flor. Coryphantha glassii se distingue por las longitudes mayores de las espinas centrales, el color amarillento de las espinas, el color amarillento brillante de sus flores y sus tubérculos cilíndricos, mientras que C. jalpanensis presenta espinas de color blanquecino, tubérculos cónicos y sus flores son de color amarillento pálido. Consideramos que estas diferencias ameritan que C. glassii sea tratada como subespecie de C. jalpanensis. 


\section{CONCLUSIONES}

Los resultados aquí obtenidos son el primer análisis multivariado, amplio e inclusivo, para circunscribir las especies del género Coryphantha. Un conjunto de 17 caracteres cuantitativos y 11 cualitativos se revelan como significativos para aplicarlos y combinarlos en la identificación de las especies. A partir de las propuesta taxonómica de Dicht y Lüthy (2001, 2005a), nuestros resultados actuales confirman la existencia de 45 especies y tres subespecies de Coryphantha. Ante las hipótesis filogenéticas recientes respecto a que Coryphantha probablemente no es monofilético (Bárcenas et al., 2011; Vázquez-Sánchez et al., 2013), nuestra siguiente meta es presentar un análisis filogenético del género a partir del conocimiento y delimitación de especies aquí obtenido y entonces generar una síntesis taxonómica robusta.

\section{AGRADECIMIENTOS}

Este trabajo constituye un requisito de la primera autora para la obtención del grado de Doctora en Ciencias del Posgrado en Ciencias Biológicas de la Universidad Nacional Autónoma de México. Balbina Vázquez-Benítez agradece el apoyo recibido al Consejo Nacional de Ciencia y Tecnologíapor la beca otorgada. Agradecemos a Ulises Guzmán, Daniel Sánchez y David Aquino por el apoyo en el trabajo de campo. Estudio financiado por el Programa UNAM-DGAPA-PAPIIT < IN208315> (SA). Se agradece a los revisores anónimos por sus comentarios y sugerencias que enriquecieron este trabajo.

\section{LITERATURA CITADA}

Arias, S., S. Gama-López, L. U. Guzmán-Cruz y B. Vázquez-Benítez. 2012. Cactaceae. In: Medina, R. (ed.). Flora del Valle de Tehuacán-Cuicatlán 95. Universidad Nacional Autónoma de México. México, D.F., México. 235 pp.

Backeberg, C. 1948. Neolloydia pulleineana. The Spine 1: 108.

Bárcenas, R., C. Yesson y J. Hawkins. 2011. Systematics of the Cactaceae. Cladistics 27: 1-20.

Barker, H. R. y B. M. Barker. 1984. Multivariate analysis of variance (MANOVA): a practical guie to its use in scientific decision-making. The University of Alabama Press. Birmingham, USA. 129 pp.

Barthlott, W. y D. Hunt. 2000. Seed-diversity in the Cactaceae. Subfam. Cactoideae. Succulent Plant Research 5: 1-173. 
Benson, L. 1982. The Cacti of the United States and Canada. Stanford University Press. Stanford, USA. 1044 pp.

Boedeker, F. 1929. Coryphantha roederiana. Monatsschrift der Deutschen KakteenGesellschaft 1: 153.

Boedeker, F. 1930a. Coryphantha speciosa. Monatsschrift der Deutschen KakteenGesellschaft 2: 23.

Boedeker, F. 1930b. Coryphantha obscura. Monatsschrift der Deutschen KakteenGesellschaft 2: 25.

Bravo-Hollis, H. y H. Sánchez-Mejorada. 1991. Las Cactáceas de México. Vol. 2, 2 da ed. Universidad Nacional Autónoma de México. México, D.F., México. 643 pp.

Bremer, L. 1980. Descripciones de Coryphantha X. Cactáceas y Suculentas Mexicanas 23: 68-72.

Bremer, L. y A. Lau. 1977. Coryphantha gracilis sp. nov. A new species from Chihuahua, México. Cactus and Succulent Journal (Los Angeles) 49: 71-73.

Buffa, L. M., P. Jaureguiberry y M. A. Delfino. 2009. Exudate gathering ants (Hymenoptera; Formicidae) at three different liquid food rewards. Acta Zoológica Mexicana 25(3): 515-526.

Butterworth, C. A., H. Cota-Sánchez y R. Wallace. 2002. Molecular Systematics of tribe Cacteae (Cactaceae: Cactoideae): A phylogeny based on rpll6 intron sequence variation. Systematic Botany 27(2): 257-270.

Butterworth, C. A. y R. Wallace. 2004. Phylogenetic studies of Mammillaria (Cactaceae) -insights from chloroplast sequence variation and hypothesis testing using the parametric bootstrap. American Journal of Botany 91(7): 1086-1098.

Buxbaum, F. 1951. Die Phylogenie der nordamerikanischen Echinocacteen. Trib. Euechinocactineae F. Buxb. Oesterreichische Botanische Zeitschrift 98: 61.

Dicht, R. y A. Lüthy. 2001. The genus Coryphantha (Engelm.) Lem. Cactaceae Systematics Initiatives 11: 7-21.

Dicht, R. y A. Lüthy. 2005a. Coryphantha. Cacti of Mexico and Southern USA. SpringerVerlag. Berlin, Alemania. 200 pp.

Dicht, R. y A. Lüthy. 2005b. The Coryphantha elephantidens group. A nomenclatural challenge. Cactus and Succulent Journal (Los Angeles) 77(3): 121-126.

Engelmann, G. 1856. Synopsis of the Cactaceae of the territory of the United States and adjacent regions. Proceedings of the American Academy of Arts and Sciences 3: 259-346.

Glass, C. 1968. Cactáceas mexicanas poco conocidas. Cactáceas y Suculentas Mexicanas 13(2): 34-35.

González, M. A. 2004. Cactáceas del estado de Nuevo León: riqueza, patrones de distribución y conservación. Tesis de licenciatura. Universidad Autónoma de Nuevo León. Linares, México. 389 pp.

Guzmán, U., S. Arias y P. Dávila. 2003. Catálogo de cactáceas mexicanas. Universidad Nacional Autónoma de México y Comisión Nacional para el Conocimiento y Uso de la Biodiversidad. México, D.F., México. 315 pp.

Hernández-Hernández, T., H. M. Hernández, J. A. De-Nova, R. Puente, L. E. Eguiarte y S. Magallón. 2011. Phylogenetic relationships and evolution of growth form in 
Cactaceae (Caryophyllales, Eudicotyledoneae). American Journal of Botany 98(1): 44-61.

Hunt, D. 2006. The New Cactus Lexicon. David Hunt books. Milborne Port, Inglaterra. 373 pp.

Lemaire, C.1868. Les cactées. Librairie Agricole de la Maison Rustique. Paris, Francia. 36 pp.

Pickett, H. y D. Clark. 1979. The function of extrafloral nectaries in Opuntia acanthocarpa (Cactaceae). American Journal of Botany 66(6): 618-625.

Quehl, L. 1908. Mammillaria difficilis Quehl n. sp. Monatsschrift für Kakteenkunde 18: 107.

Rohlf, F. J. 1998. NTSYS-PC. Numerical taxonomy and multivariate analysis system. Versión 2.0. User Guide. Exeter Software. Applied Biostatistics Inc. New York, USA.

Rudall, P. J. 2009. Anatomía de las plantas con flores: Introducción a la estructura y el desarrollo. Prensas Universitarias de Zaragoza. Zaragoza, España. 160 pp.

Rzedowski, J. 1978. Vegetación de México. Limusa. México, D.F., México. 432 pp.

Schmalzel, R. J., R. T. Nixon, A. L. Best y Tress J. A. 2004. Morphometric variation in Coryphantha robustispina (Cactaceae). Systematic Botany 29(3): 553-568.

Statpoint, Inc. 2005. STATGRAPHICS Centurion XV Version 15.0.04. http://www. statgraphics.com

Vázquez-Sánchez, M., T. Terrazas, S. Arias y H. Ochoterena. 2013. Molecular phylogeny, origin, and taxonomic implications of the tribe Cacteae (Cactaceae). Systematics and Biodiversity 11(1): 103-116.

Zeiss, C. 2009. AxioVision Imaging System. Release 4.8. http://www.zeiss.de/axiovision Zimmerman, A. D. 1985. Systematics of the genus Coryphantha. Ph. D. Thesis. University of Texas. Austin, USA. 447 pp. 


\section{APÉNDICE}

Especies y localidades analizadas para el presente estudio. Todos los registros están depositados en el Herbario Nacional de México (MEXU). Los números dentro de los paréntesis marcados con * en C. robustispina indican los ejemplares empleados en este estudio.
Especie
Colector, número y localidad
(ubicación, estado)
C. bumamma (C. Ehrenb.) Britton \& Rose
C. calipensis Bravo ex S. Arias et al.
C. clavata (Scheidw.) Backeb.
C. compacta (Engelm.) Britton \& Rose
C. cuencamensis L. Bremer
C. delaetiana (Quehl) A. Berger
C. delicata $\mathrm{L}$. Bremer
C. difficilis (Quehl) A. Berger
C. durangensis (Runge ex K. Schum.) Britton \& Rose
C. echinoidea (Quehl) Britton \& Rose
C. echinus (Engelm.) Britton \& Rose
C. elephantidens (Lem.) Lem.
C. erecta (Lem.) Lem.
C. georgii Boed.
C. glanduligera (Otto \& A. Dietr.) Lem.
C. glassii Dicht \& A. Lüthy
C. gracilis L. Bremer \& A.B. Lau
C. greenwoodii Bravo
C. hintoniorum Dicht \& A. Lüthy
C. jalpanensis Buchenau
C. kracikii Halda, Chalupa \& Kupcak
C. longicornis Boed.
C. macromeris (Engelm.) Lem.
C. maiz-tablasensis Backeb.
C. neglecta L. Bremer
C. nickelsiae (K. Brandegee) Britton \& Rose
C. octacantha (DC.) Britton \& Rose
Vázquez 2628, Zumpango del Río, Gro.
Vázquez 2555, Cuicatlán, Oax.
Vázquez 2529, Rioverde, S.L.P.
Vázquez 2608, San Buenaventura, Chih.
Vázquez 2627, Cuencamé, Dgo.
Arias 1904, Tlahualilo, Dgo.
Vázquez 2546, Cedral, S.L.P.
Vázquez 2541, General Cepeda, Coah.
Vázquez 2626, Nazas, Dgo.
Vázquez 2514, San Pedro, S.L.P.
Arias 2072, Ojinaga, Chih.
Vázquez 2629, Jantetelco, Gro.
Vázquez 2640, San Luis de la Paz, Gto.
Vázquez 2517, Guadalcázar, S.L.P.
Vázquez 2547, Matehuala, S.L.P.
Vázquez 2525, Rioverde, S.L.P.
Vázquez 2585, Valle del Rosario, Chih.
Vázquez 2630, Acultzingo, Ver.
Vázquez 2539, Galeana, N.L.
Vázquez 2586, Arroyo Seco, Qro.
Vázquez 2618, Villa Hidalgo, Dgo.
Vázquez 2623, Indé, Dgo.
Vázquez 2540, General Cepeda, Coah.
Vázquez 2560, Rioverde, S.L.P.
Arias 2105, Cuatrociénegas, Coah.
Vázquez 256,5 Mina, N.L.
Vázquez 2531, Santiago de Anaya, Hgo. 
Apéndice. Continuación.

\begin{tabular}{|c|c|}
\hline Especie & $\begin{array}{l}\text { Colector, número y localidad } \\
\text { (ubicación, estado) }\end{array}$ \\
\hline C. ottonis (Pfeiff.) Lem. & Vázquez 2588, Axapusco, Edo. Méx. \\
\hline C. pallida Britton \& Rose & Vázquez 2590, Zapotitlán, Pue. \\
\hline C. poselgeriana (A. Dietr.) Britton \& Rose & Vázquez 2544, General Cepeda, Coah. \\
\hline C. potosiana (Jacobi) Glass \& R.A. Foster & Guzmán 2771, Villa de Arriaga, S.L.P. \\
\hline C. pseudoechinus Boed. & Vázquez 2542, General Cepeda, Coah. \\
\hline C. pseudonickelsiae Backeb. & Vázquez 2620, Indé, Dgo. \\
\hline C. pseudoradians Bravo & Vázquez 2637, Suchixtlahuaca, Oax. \\
\hline C. pulleineana (Backeb.) Glass & Vázquez 2593, Guadálcazar, S.L.P. \\
\hline C. pycnacantha (Mart.) Lem. & Vázquez 2589, Axapusco, Edo. Méx. \\
\hline C. radians (DC.) Britton \& Rose & Guzmán 3164, Cadereyta, Qro. \\
\hline C. ramillosa Cutak & Arias 1967, Cuatrociénegas, Coah. \\
\hline C. recurvata (Engelm.) Britton \& Rose & Vázquez 2575, Imuris, Son. \\
\hline C. retusa (Pfeiff.) Britton \& Rose & Vázquez 2558, Santiago Miltepec, Oax. \\
\hline $\begin{array}{l}\text { C. robustispina }(1)^{*} \text { (Ant. Schott ex Engelm.) } \\
\text { Britton \& Rose }\end{array}$ & Vázquez 2577, Sásabe, Son. \\
\hline C. robustispina $(9)^{*}$ & Vázquez 2581, Villa Ahumada, Chih. \\
\hline $\begin{array}{l}\text { C. salinensis (Poselg.) A. D. Zimmerman ex } \\
\text { Dicht \& A. Lüthy }\end{array}$ & Vázquez 2566, Mina, N.L. \\
\hline C. sulcata (Engelm.) Britton \& Rose & Arias 2162, Linares, N.L. \\
\hline C. tripugionacantha A.B. Lau & Arias 1878, Valparaíso, Zac. \\
\hline C. vaupeliana Boed. & Vázquez 2564, Jaumave, Tamps. \\
\hline C. vogtherriana Werderm. \& Boed. & Vázquez 2538, San Pedro, S.L.P. \\
\hline C. werdermannii Boed. & Arias 2104, Cuatrociénegas, Coah. \\
\hline C. wohlschlageri Holzeis & Vázquez 2587, Villa Juárez, S.L.P \\
\hline
\end{tabular}


